\title{
Choosing an optimal land-use pattern for restoring eco-environments in a semiarid region of the Chinese Loess Plateau
}

\author{
Yunqiang Wang a,b,c,*, Ming'an Shao ${ }^{\mathrm{b}}$, Chencheng Zhang ${ }^{\mathrm{c}}$, Xiangwei Han ${ }^{\mathrm{b}}$, \\ Tianxu Mao ${ }^{\mathrm{c}}$, Xiaoxu Jia ${ }^{\mathrm{b}}$ \\ a State Key Laboratory of Loess and Quaternary Geology, Institute of Earth Environment, Chinese Academy of Sciences, Xi'an, Shaanxi 710075, China \\ ${ }^{\mathrm{b}}$ Key Laboratory of Ecosystem Network Observation and Modeling, Institute of Geographic Sciences and Natural Resources Research, Chinese Academy of \\ Sciences, Beijing 100101, China \\ ' State Key Laboratory of Soil Erosion and Dryland Farming on the Loess Plateau, Institute of Soil and Water Conservation, Chinese Academy of Sciences E' \\ Ministry of Water Resources, Yangling 712100, China
}

\section{A R T I C L E I N F O}

\section{Article history:}

Received 9 May 2014

Received in revised form 20 September 2014 Accepted 1 October 2014

Available online 29 October 2014

\section{Keywords:}

Deep soils

Dried soil layer

Aboveground net primary productivity

Soil water

Grassland

Shrubland

\begin{abstract}
A B S T R A C T
The natural environments in the semiarid regions of the Chinese Loess Plateau (CLP) are fragile due to the serious soil erosion and the weak ecological services of the plants. To ascertain and then evaluate a sustainable land-use pattern in these regions, we selected six typical land-use patterns (i.e., a farmland, a natural grassland, a homogeneous shrubland ( $\mathrm{S}$ ), a mix of shrubland and cultivated grassland (S-Alf), a mix of shrubland and orchard (S-O) and a mix of shrubland and grassland $(\mathrm{S}-\mathrm{G})$ ) on the plateau and then measured the soil water, related soil properties and plant root indices to a depth of $1800 \mathrm{~cm}$. We also measured the aboveground net primary productivities (ANPPs). The mean soil water content (SWC) within the $0-1800 \mathrm{~cm}$ profile was significantly highest (15.2\%) in farmland, followed by grassland (11.4\%) and S-Alf (8.0\%). The available water (AW), the ratio between AW and AW capacity, and the thickness of the dried soil layers also demonstrated that farmland had the best conditions of soil water, followed by grassland and shrubland. The aboveground biomasses of grassland in both non-growing $\left(140 \mathrm{~g} \mathrm{~m}^{-2}\right)$ and growing $\left(370 \mathrm{~g} \mathrm{~m}^{-2}\right)$ seasons were significantly higher than those of shrublands. The ANPPs of the grassland $\left(2.0 \mathrm{~g} \mathrm{~m}^{-2} \mathrm{~d}^{-1}\right)$ demonstrated a similar trend. The patterns of land use (including the mixtures of different plant species) greatly affected the patterns of vertical distribution and quantities of soil water within the $1800-\mathrm{cm}$ profile. The data for the soil-water regime and the ANPP further indicated that grassland would be an optimal use of the land for these semiarid regions. This information should be useful to the ecological scientists and policy makers for developing strategies for the sustainable management of vegetation on the CLP and possibly other water-limited regions around the world.
\end{abstract}

(c) 2014 Elsevier B.V. All rights reserved.

\section{Introduction}

Soil water content (SWC) depends on a number of factors such as meteorological conditions, topographical elements, soil properties and land cover (Chen et al., 2007a) and is a crucial factor affecting plant growth and many ecological and environmental processes (Hu et al., 2010). Plants in turn affect soil water by forming a preferential pathway for the transport of soil water to the atmosphere via their root systems, which results from a

\footnotetext{
* Corresponding author at: Institute of Earth Environment, Chinese Academy of Sciences, State Key Laboratory of Loess and Quaternary Geology, 10 Fenghui South Road, Xi'an High-Tech Zone, Xi'an, Shaanxi 710075, China Tel.: +86 2988325936 ; fax: +86 2988325936.

E-mail address: wangyunq04@163.com (Y. Wang).
}

number of complex and mutually interacting physiological and ecological processes (Stephen et al., 2001). Information on the levels, distributions, and dynamics of SWC within soil profiles is thus vital for the sustainable management of water resources, strategies of revegetation, and hydrological, ecological and climatic modeling (Josa et al., 2012; Wang et al., 2013).

In water-limited arid and semiarid environments and some humid regions where water shortage occurs seasonally, the role of the uptake of deep water $(>800 \mathrm{~cm})$ by roots has been a major discovery during the last 20 years (Nepstad et al., 1994). Considerable interest has since been generated around the world in the assessment of vertical distribution and influencing factors ( $\mathrm{Li}$ et al., 2008; Yang et al., 2012), depletion and replenishment (Li and Huang, 2008; Liu et al., 2010), dynamics and simulations (Jipp et al., 1998; Markewitz et al., 2010; Zhao et al., 2008) of SWC in soils to a depth of roughly $1000 \mathrm{~cm}$. The depth of depletion of SWC, inferred 
to be a function of root uptake, has recently been reported to be $1800 \mathrm{~cm}$ in an Amazonian forest (Davidson et al., 2011) and to be 1550, 2240 and $2150 \mathrm{~cm}$ (based on the comparison of soil-water conditions between shrublands/forests and permanent farmland) in alfalfa grassland, Caragana korshinskii shrubland and pine forest, respectively, on the Loess Plateau of China (Wang et al., 2009).

The increasing depth of depletion of SWC within a soil profile by plants is a feedback of negative water balance (Davidson et al., 2011 ) which may result in a decrease in inputs (i.e., rainfall) and/or an increase in outputs (i.e., evapotranspiration) (Liu and Sang, 2013; Wang et al., 2011). The formation of a dried soil layer (DSL) was reported to be a typical response to the negative water balance (Li, 1983). Definitions, basic characteristics, dynamics, evolution, regional distributions and factors influencing the DSL have been reported (Chen et al., 2008; Wang et al., 2008; Wang et al., 2011), but the sampling depth in most published studies was shallower than $1000 \mathrm{~cm}$.

The level of negative water balance may be aggravated by (1) the ongoing global warming that is generally, but not universally, expected to increase evapotranspiration and thus cause declines in SWC (Breshears et al., 2005; Zavaleta et al., 2003) and (2) the irrational management of land such as planting trees at high densities and introducing exotic species that may extract a large amount of deep soil water over short periods of time (Chen et al., 2008; Wang et al., 2008). Deeper soil water participates in biogeochemical processes via root systems of plants that generally extend below $1000 \mathrm{~cm}$ in regions covered by deep soils. The quantity and distribution pattern of SWC and its response to environmental factors in soils below $1000 \mathrm{~cm}$, however, are not clear, but this information is increasingly needed.

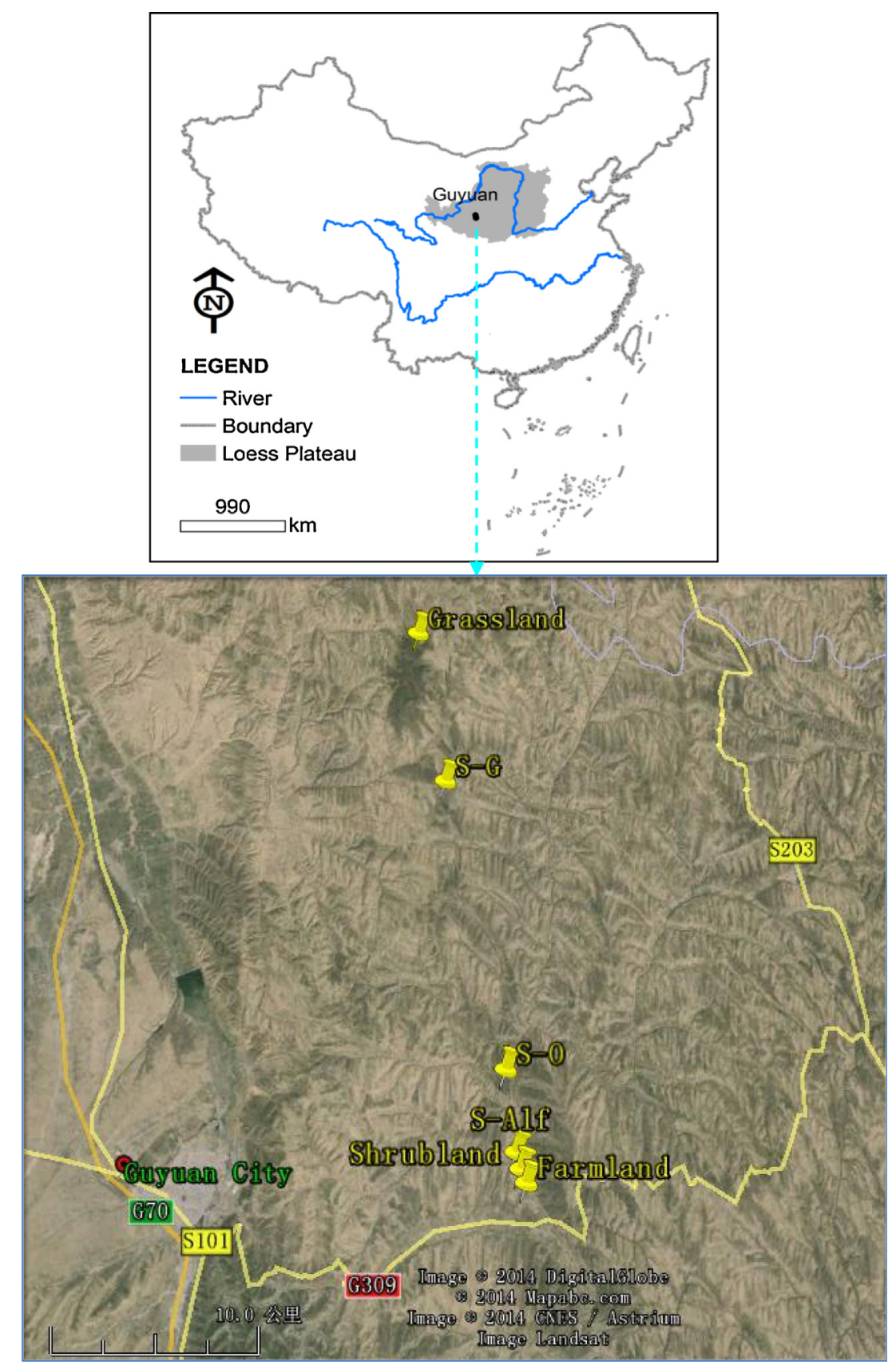

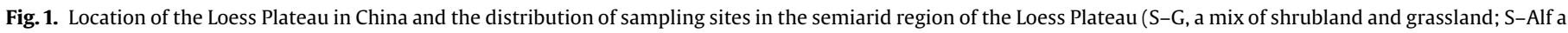
mix of shrubland and cultivated grassland, S-O: a mix of shrubland and orchard). 
The Chinese Loess Plateau (CLP) is a well-known water-limited region (Shi and Shao, 2000). Its ecosystem is fragile due to (1) serious soil erosion caused by the seasonal distribution of rainfall and the properties of the loessial soils, (2) low coverage, productivity and ecological services of the vegetation and (3) frequent and intensive human disturbance (Chen et al., 2007b). To control soil erosion and restore the natural environments on the plateau, the Chinese government has launched a number of ecological construction projects since the 1980s. A notable project was the "Grain-for-Green" program initiated in 1999, which has achieved significant improvements in the natural environment in some regions of the CLP. Since then, wide areas of cultivated land have been converted to forests/shrublands (some exotic species were irrationally introduced, which would exhaust more soil water to maintain growth, e.g., C. korshinskii) or grasslands (some pastoral species with high water-consumption capacity were also planted, e.g., alfalfa) (Lu et al., 2012). The widespread planting of vegetation, however, has further aggravated the demand on soil water in both the upper and deeper soil layers and has thus led to the occurrence of DSLs on regional scales (Wang et al., 2011). The CLP is a natural experimental site for investigating the status of deep soil water and its controlling processes, due to its deep loesspaleosol deposits generally ranging from 30 to $80 \mathrm{~m}$ in thickness (Chen et al., 2007a).

The impacts of meteorological conditions, soil properties, topographical elements and land uses on the conditions of the soil water have been intensively studied and are generally understood. For example, past studies have generally shown an order of forest $<$ shrub $<$ grassland $<$ cultivated soils for soil water in upper few meters of soil (Chen et al., 2009; Yang et al., 2012). Most studies of land-use patterns, however, did not systematically consider the regimes of deep SWC, the extent of DSL or the aboveground net primary productivity (ANPP) of the dominant species. More recently, Zhang et al. (2014) evaluated the cumulative effects of different engineering runoff-control practices on SWC $(0-200 \mathrm{~cm})$ and plant growth and suggested that afforestation may lead to an over-consumption of soil water that could potentially cause the soil to dry. Their study further indicates an increasing need to investigate the levels of DSLs under different site conditions.

In current study, we have focused on ascertaining the influence of land-use patterns (including the mixtures of different plant species) on deep soil water (especially below $1000 \mathrm{~cm}$ ) and then finding an optimal land-use pattern for restoring eco-environments in the water-limited regions by comprehensively determining the levels of deep SWC, DSL and ANPP under different land-use patterns. The specific purposes of this study were (1) to investigate the distribution and amounts of deep soil water to a depth of $1800 \mathrm{~cm}$, which was the maximum depth reached by roots in 33 measured sites across the CLP (Wang et al., 2013), and (2) to ascertain and evaluate a sustainable land-use pattern for restoring the natural environment in this region based on the measured SWC and DSL within $0-1800 \mathrm{~cm}$ soil profiles and on the ANPP data.
Knowledge of the effects of land-use patterns on deep soil water would help us to understand the dynamics, cycling and fate of deep water and allow us to address the long-term sustainable management of water resources.

\section{Materials and methods}

\subsection{Study area and site selection}

The study was conducted near the city of Guyuan in Ningxia Province of northwestern China (Fig. 1). This area is in the "hill and gully" region of the CLP and is in the semiarid continental monsoon region. The mean annual precipitation and temperature are $433.8 \mathrm{~mm}$ and $6.5^{\circ} \mathrm{C}(1970-2001)$, respectively. The soil, characterized by deep loess-paleosol deposits, is easily eroded due to its weak cohesion and high infiltrability (Fang et al., 2012). The water table is below $50 \mathrm{~m}$, so the stocks of soil water available to plants are recharged only by rainwater.

This area is ideal for investigating the influence of land-use patterns on the status of deep soil water, because many types of restoration measures have been conducted in this region in the last three decades for determining a sustainable means of revegetation (Jing et al., 2013; Xue et al., 2013). We selected six common and typical land-use patterns (the area of each pattern was greater than $100 \times 100 \mathrm{~m}$ ) for collecting samples of plants and deep soil and then evaluated their soil-water regimes to a depth of $1800 \mathrm{~cm}$ and the aboveground ANPPs. The six land-use patterns were: farmland (planted with buckwheat), grassland (planted with Stipa bungeana), homogeneous shrubland (S) (planted with C. korshinskii), a mix of shrubland and cultivated grassland (S-Alf) (interplanted with $C$. korshinskii and alfalfa (Medicago sativa)) a mix of shrubland and orchard (S-O) (interplanted with C. korshinskiiPrunus armeniaca), and a mix of shrubland and grassland (S-G) (interplanted with C. korshinskii-S. bungeana). The minimum and maximum distances among the six patterns were 50 and $0.8 \mathrm{~km}$, respectively (Fig. 1), reflecting a low variation of climatic conditions. The site conditions (e.g., topographical elements and characteristics of the vegetation) of each pattern were similar (see Table 1), allowing us to evaluate the impacts of the land-use patterns on soil water. Fig. 2 presents photographs of the six selected patterns for measuring aboveground biomasses (except the farmland) during the non-growing and growing seasons.

\subsection{Experimental data for soil, roots and aboveground biomass}

Disturbed soil samples were collected at the center of each land-use pattern using a soil auger $(10 \mathrm{~cm}$ in diameter) to a depth of $1800 \mathrm{~cm}$ (for the shrublands, the sampling position was $0.5 \mathrm{~m}$ from the representative $C$. korshinskii bushes). Samples for determining SWC were removed at $10-\mathrm{cm}$ intervals for the $0-20 \mathrm{~cm}$ layer, $20-\mathrm{cm}$ intervals for the $20-600 \mathrm{~cm}$ layer and $25-\mathrm{cm}$ intervals for the $600-1800 \mathrm{~cm}$ layer. Samples for measuring soil organic carbon (SOC) content and soil particle composition

Table 1

Site conditions of the six selected land-use patterns in the semiarid region of the the Loess Plateau.

\begin{tabular}{|c|c|c|c|c|c|c|c|c|}
\hline Land-use pattern & Slope position & Altitude (m a.s.l.) & Vegetation & Plant age & Root depth $(\mathrm{cm})$ & Proportion $^{\mathrm{a}}$ & Coverage & Sampling date \\
\hline Farmland & Upslope & 1652 & Buckwheat (Triticum aestivum) & $>30$ & 120 & - & $>85$ & $2011-8-27$ \\
\hline Grassland & Topslope & 2127 & Stipa bungeana & $>30$ & 220 & - & $>95$ & $2011-8-26$ \\
\hline Shrubland & Topslope & 1660 & Caragana korshinskii & $>30$ & 1800 & - & $>80$ & $2011-8-23$ \\
\hline$S-G$ & Upslope & 1874 & C. korshinskii,S. bungeana & $>30$ & 560 & $1: 3$ & $>80$ & $2011-8-24$ \\
\hline S-Alf & Upslope & 1622 & C. korshinskii, Medicago sativa & $>20$ & 1550 & $1: 2.5$ & $>85$ & $2011-8-21$ \\
\hline $\mathrm{S}-\mathrm{O}$ & Upslope & 1695 & C. korshinskii, Prunus armeniaca & $>20$ & 600 & $2: 1$ & $>90$ & $2011-8-22$ \\
\hline
\end{tabular}

Note: S-G, a mix of shrubland and grassland; S-Alf, a mix of shrubland and cultivated grassland; S-O, a mix of shrubland and orchard.

a The proportions of the mixtures among C. korshinskii and S. bungeana, Medicago sativa L. or Prunus armeniaca. 

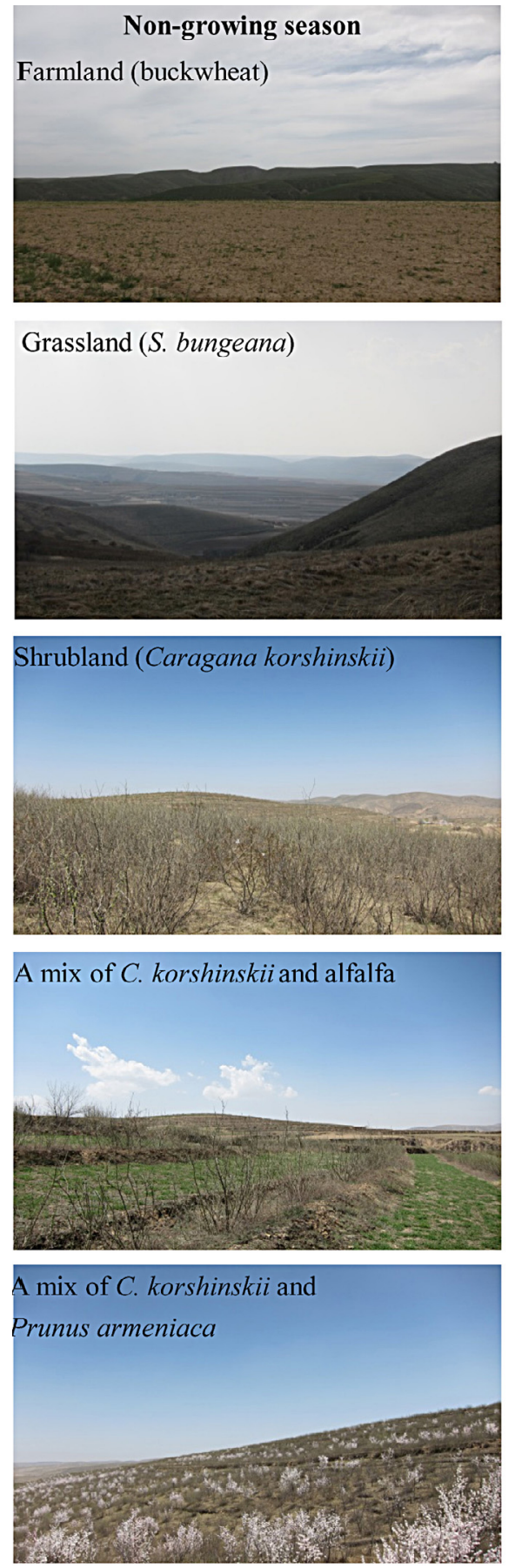

A mix of C. korshinskii and S. bungeana

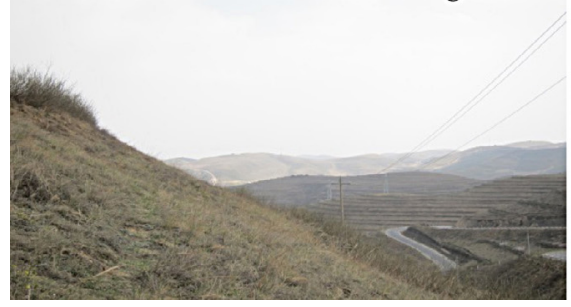

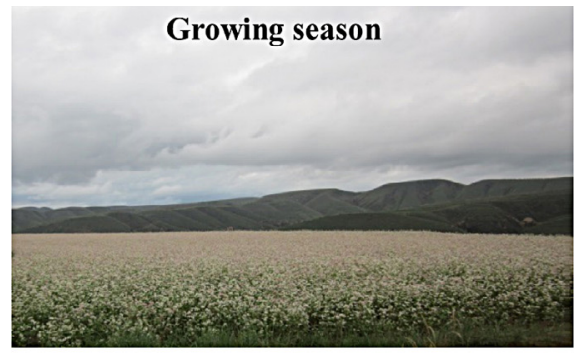
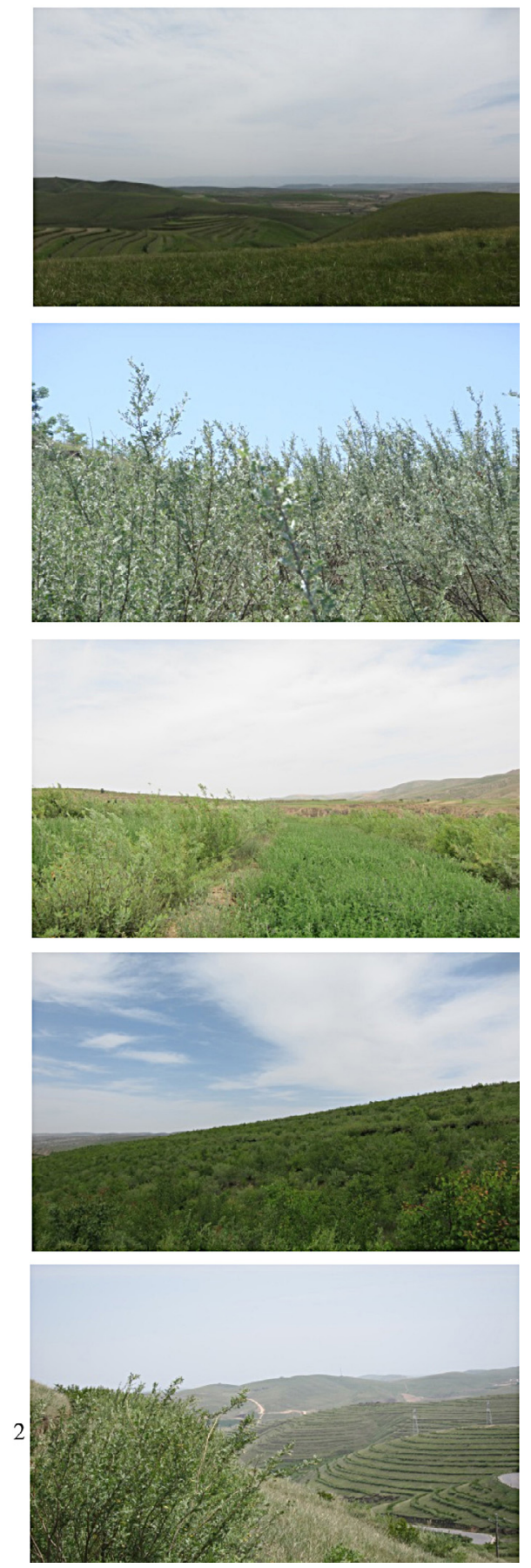

Fig. 2. Photographs of the selected six sites for measuring aboveground biomasses during the non-growing and growing seasons. 
were collected from the same depths, but the sampling interval was $50 \mathrm{~cm}$ for the $600-1800 \mathrm{~cm}$ layer. Totals of 79 samples for determining SWC and 55 samples for determining SOC content and soil particle composition were collected for each pattern.

The depth to which plant roots extended was recorded at the time of soil sampling. Samples of plant roots were collected from the soil samples at the same intervals as the samples for determining SOC content.

The gravimetric soil water content ( $\mathrm{g} \mathrm{H}_{2} \mathrm{O} / 100$ g dry soil, \%), soil particle composition, SOC content and live-root biomasses were measured in the laboratory by oven-drying, laser diffraction, the dichromate-oxidation method and weighing, respectively, as described in detail in Wang et al. (2011).

We only collected soil samples at one $1800-\mathrm{cm}$ profile for each pattern, due to the intensive labor of directly collecting deep soil samples. The SWC was thus not replicated in the field. SWC measured in a single profile, however, can, to large extent, reflect the soil-water condition of the land-use pattern, because the variation of SWC (especially for deep SWC) on a local scale in a homogeneous landscape (i.e., in our case) is generally considered to be weak.

During the non-growing (April) and growing seasons (August), we collected the aboveground biomasses of $C$. korshinskii from three $5 \times 5 \mathrm{~m}$ quadrats in the shrublands. We also collected aboveground biomasses of the grassland from three $1 \times 1 \mathrm{~m}$ quadrats. The locations of the three replicate quadrats were selected randomly for each land-use pattern. All the above plant samples were dried at $65^{\circ} \mathrm{C}$ in an oven for $72 \mathrm{~h}$ to estimate dry weight. We calculated the ANPPs of $C$. korshinskii and the grassland in $\mathrm{g} \mathrm{m}^{-2} \mathrm{~d}^{-1}$ for the period from the non-growing to the growing seasons.

\subsection{Evaluation indices of soil water}

The evaluation indices of the soil water were SWC, available soil water (AW) (which can directly reflect how much soil water can be used by a plant) and the thickness of the DSL (DSLT) (which can effectively reflect the extent of soil desiccation). The calculation of $\mathrm{AW}$ requires information for the $\mathrm{SWC}$ at field capacity, $\mathrm{SWC}_{\mathrm{FC}}$ (=volumetric SWC at $-0.03 \mathrm{MPa}$ ), and the SWC at the wilting point, $\mathrm{SWC}_{\mathrm{WP}}$ (= volumetric SWC at $-1.5 \mathrm{MPa}$ ) (Grassini et al., 2010). The direct measurement of $S W C_{F C}$ and $S W C_{W P}$ within the $1800-\mathrm{cm}$ profile was a practical challenge (i.e., the collection of undisturbed soil cores), so we estimated their values by using pedotransfer functions (PTFs) where the measured SOC contents and soil particle compositions were the basic inputs. The selection procedures of the PTFs for $S W C_{F C}$ and $S W C_{W P}$ are described in detail in Wang et al. (2013). The level of accuracy of the PTFs for the $\mathrm{SWC}_{\mathrm{FC}}$ and $\mathrm{SWC}_{\mathrm{WP}}$ predictions (SOC and clay content were the inputs) was acceptable at a significance level of $P=0.05$. We could then calculate the values of AW and the available soil waterholding capacity (ASWC) as:

$\mathrm{AW}=\mathrm{SWC}_{\mathrm{FC}}-\mathrm{SWC}(1)$

$\mathrm{ASWC}=\mathrm{SWC}_{\mathrm{FC}}-\mathrm{SWC}_{\mathrm{WP}}(2)$

We assumed that $S W C_{W P}$ was equal to the minimum value of measured SWC among the studied profiles, because some droughtadapted species growing on the Loess Plateau can extract soil water at pressures below -1.5 MPa. This phenomenon has been reported in Cheng et al. (2009).A DSL has a range of SWC between $S_{W} C_{W P}$ and the stable field capacity (SFC), which is generally considered to be equivalent to $60 \%$ of the $\mathrm{SWC}_{\mathrm{FC}}$ for loam soil. A soil layer with an SWC lower than the SFC would thus be considered a DSL. The DSLT is calculated by:
$\mathrm{DSLT}=\sum_{i=6}^{n} \mathrm{~K}\left(\mathrm{SWC}_{\mathrm{i}}-\mathrm{SFC}_{\mathrm{i}}\right) \times D$

where $\mathrm{K}\left(\mathrm{SWC}_{\mathrm{i}}-\mathrm{SFC}_{\mathrm{i}}\right)=\left\{\begin{array}{ll}0, & \mathrm{SWC}_{\mathrm{i}}-\mathrm{SFC}_{\mathrm{i}}>0 \\ 1, & \mathrm{SWC}_{\mathrm{i}}-\mathrm{SFC}_{\mathrm{i}} \leq 0\end{array}\right.$,

$(i=6,7,8, \ldots \ldots, n)$, and where $\mathrm{SWC}_{i}$ is the SWC of the $i$ th soil layer, $n$ is the number of sublayers for each $1800-\mathrm{cm}$ soil profile (=79) and $D$ is the thickness of the sublayer. The calculation of DSLT started at a depth of $100 \mathrm{~cm}$, corresponding to $i=6$, because the formation depth of the DSL was $100 \mathrm{~cm}$ in the study area.

\subsection{Data analysis}

Primary statistical parameters, including the mean, maximum, minimum, standard deviation (SD) and coefficient of variation (CV) of the measured SWCs, were calculated to determine the midpoint and range of the data. Skewness, kurtosis and KolmogorovSmirnov tests were used to determine the normality of the data. One-way analyses of variance were used to assess the contribution of the various land-use patterns to the overall variation in SWC. Multiple comparisons were conducted using the least significant difference (LSD) method (SPSS ${ }^{\mathbb{R}}$, version 13.0).

\section{Results and discussion}

\subsection{Vertical distributions of soil and root properties in deep soils}

\subsubsection{Soil particle composition and fresh-root weight}

Fig. 3 shows the data for the vertical distribution of soil particle composition and fresh-root weight within the entire $1800-\mathrm{cm}$ profile for each land-use pattern. Soil particle composition had a similar vertical pattern among the six land-use patterns, and the contents of clay, silt and sand were approximately 25,63 and $12 \%$, respectively (Table 2 ). The homogeneity of the soil texture in both the vertical direction (the CVs varied from 31 to $41 \%$ for sand, from 12 to $17 \%$ for clay and from 4 to $5 \%$ for silt) and among the sampling sites observed (the CVs of sand, clay and silt content were 20, 26 and $7 \%$, respectively) was high in the present study, allowing us to evaluate the impacts of the plants on the conditions of the soil water. Nosetto et al. (2005) found that the evapotranspiration (ET) in a Eucalyptus grandis plantation was more strongly affected by soil texture than by grassland ET, implying that the homogeneity of soil texture was necessary for evaluating the effect of land use on soil-water conditions.

The distributions of roots at the six land-use patterns were highly heterogeneous (Fig. 3). Root depth was shallowest in the farmland $(120 \mathrm{~cm})$, while the depth was deepest in $\mathrm{S}$, where the roots extended to at least $1800 \mathrm{~cm}$ (the maximum sampling depth used in this study). The mixed land-use pattern ( $\mathrm{S}-\mathrm{O})$ had two different root distributions; we would expect apricot trees to have shallower roots than $C$. korshinskii based on the reported rooting depths of apricot trees on the Loess Plateau (Gao and Shao, 2012). Root depth ranged from 240 to $1600 \mathrm{~cm}$ in the other land-use patterns, within the range of rooting depth from $30 \mathrm{~cm}$ for some tundra species to $6800 \mathrm{~cm}$ for Boscia albitrunac in the central Kalahari (Canadell et al., 1996). The root-distribution depth within the profile may, to some extent, reflect the pattern of the soilwater regime: the deeper the roots, the lower the SWC in the corresponding root zone. Plants use soil water naturally in the vadose zone under the drives of plant transpiration and atmospheric vapor pressure.

\subsubsection{Overall distribution of soil water}

SWC had a wide range from 3.9 to $22.5 \%$ within the $0-1800 \mathrm{~cm}$ profile (Fig. 4a). Two distinct phases were identified for the vertical distribution of the mean SWCs: (1) a phase of rapid decline 
$(0-100 \mathrm{~cm})$ where the mean SWC initially decreased rapidly with increasing soil depth, from $19.4 \%$ in the surface layer $(0-10 \mathrm{~cm})$ to $6.3 \%$ at a depth of $100 \mathrm{~cm}$, and (2) a phase of increase (100$1800 \mathrm{~cm}$ ) where the mean SWC was clearly observed to increase intermittently from 6.3 to $14.1 \%$ at a depth of $1800 \mathrm{~cm}$. The lowest mean SWC, at a depth of $100 \mathrm{~cm}$, was the combined result of plantroot distribution, soil evaporation and the infiltration and redistribution of rainwater (Wang et al., 2012b).

The mean SWC within the entire $1800-\mathrm{cm}$ profile was $11.1 \%$ ( $n=6 \times 79=474$ ) with a CV of $38 \%$ (Fig. 4 b). Variations in SWC were highest for the $200-400 \mathrm{~cm}$ layer (CV generally higher than $50 \%$ ) and decreased unevenly to the bottom layer, with $C V s=20 \%$. The high variation in SWC may be caused by the differences among the land-use patterns and the different characteristics of water uptake by the plant roots. The very weak variation of SWC in the surface 0$20 \mathrm{~cm}$ layer (mean $\mathrm{CV}=12 \%$ ) was closely associated with the sampling time after the rainy season (i.e., a high amount of soil water). The higher SWCs are less variable for the same soil type, as reported by Hu et al. (2010). Gao and Shao (2012) further reported that sampling density should be increased over time for shallower layers due to the spatial and temporal variability of SWC for different soil layers and recommended that more samples should be collected over space for the deeper soil layers.

\subsection{Impacts of land-use patterns on the soil-water regime}

\subsubsection{Soil water}

Table 3 lists the statistics of SWC under the different land-use patterns. Farmland had the highest mean SWC (15.2\%), significantly $(P<0.05)$ higher than the other five patterns. S-Alf had the lowest mean SWC (8.0\%). The SWC in S was not significantly different from that of S-Alf but the interplanting of alfalfa further decreased the SWC throughout the profile. In contrast, interplanting $S$. bungeana or $P$. armeniaca in S significantly increased the mean SWC of within each soil profile from $8.3 \%$ to 9.9 and $10.5 \%$, respectively. On the other hand, interplanting C. korshinskii on $S$. bungeana grassland significantly decreased the SWC of the profile. The vertical distribution of SWC is depicted in Fig. 5 and the
Table 2

Soil texturesof theselected land-use patterns on the Loess Plateau.

\begin{tabular}{|c|c|c|c|c|}
\hline Land use patterns & Texture & Mean (\%) & $\mathrm{SD}(-)$ & $\mathrm{CV}(\%)$ \\
\hline \multirow[t]{3}{*}{ Farmland } & Sand & 12.0 & 4.6 & 38 \\
\hline & Clay & 29.8 & 3.6 & 12 \\
\hline & Silt & 58.2 & 2.3 & 4 \\
\hline \multirow[t]{3}{*}{ Grassland } & Sand & 17.2 & 5.4 & 32 \\
\hline & Clay & 12.0 & 3.3 & 27 \\
\hline & Silt & 70.8 & 3.1 & 4 \\
\hline \multirow[t]{3}{*}{ Shrubland } & Sand & 11.4 & 4.7 & 41 \\
\hline & Clay & 26.6 & 3.6 & 14 \\
\hline & Silt & 62.0 & 3.0 & 5 \\
\hline \multirow[t]{3}{*}{$S-G$} & Sand & 10.6 & 3.3 & 31 \\
\hline & Clay & 29.6 & 3.4 & 12 \\
\hline & Silt & 59.8 & 2.4 & 4 \\
\hline \multirow[t]{3}{*}{ S-Alf } & Sand & 10.7 & 4.1 & 38 \\
\hline & Clay & 25.6 & 3.4 & 13 \\
\hline & Silt & 63.7 & 2.9 & 5 \\
\hline \multirow[t]{6}{*}{$\mathrm{S}-\mathrm{O}$} & Sand & 12.7 & 4.5 & 35 \\
\hline & Clay & 25.1 & 4.4 & 17 \\
\hline & Silt & 62.2 & 2.5 & 4 \\
\hline & Sand & 12.4 & 2.5 & 20 \\
\hline & Clay & 24.8 & 6.6 & 26 \\
\hline & Silt & 62.8 & 4.4 & 7 \\
\hline
\end{tabular}

Note: S-G, a mix of shrubland and grassland; S-Alf, a mix of shrubland and cultivated grassland; $\mathrm{S}-\mathrm{O}$, a mix of shrubland and orchard; SD, standard deviation; $\mathrm{CV}$, coefficient of variation.

quantity of AW presented in Fig. 6 indicated that soil-water regimes depended highly on the plant species of the land-use patterns. The AW in the farmland was the highest, followed by grassland, and the AW in S was the lowest; this trend was consistent with the results of Yang et al. (2012) whose SWC data was based on a $0-800 \mathrm{~cm}$ soil profile (which may reflect plant-root development to some extent). AW in the mixed land-use patterns was in the order $\mathrm{S}-\mathrm{O}>\mathrm{S}-\mathrm{G}>\mathrm{S}-$ Alf. Such trends in soil water were

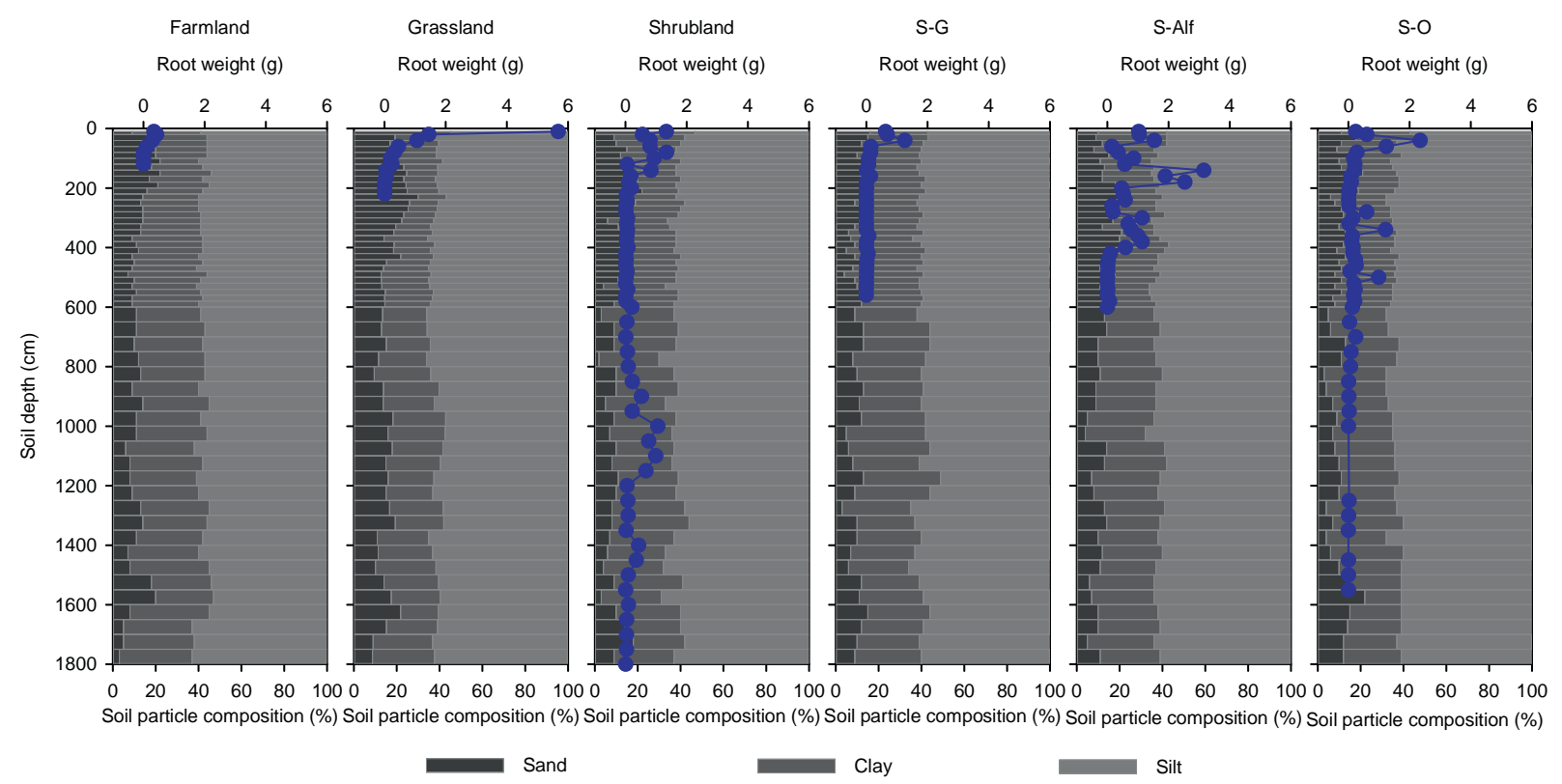

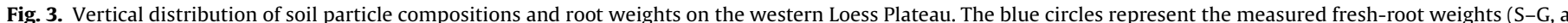

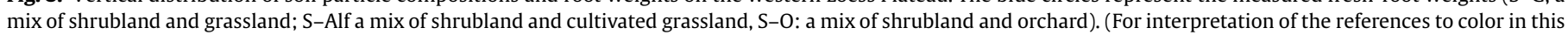
figure legend, the reader is referred to the web version of this article.) 
(a) Soil water content $(\%)$

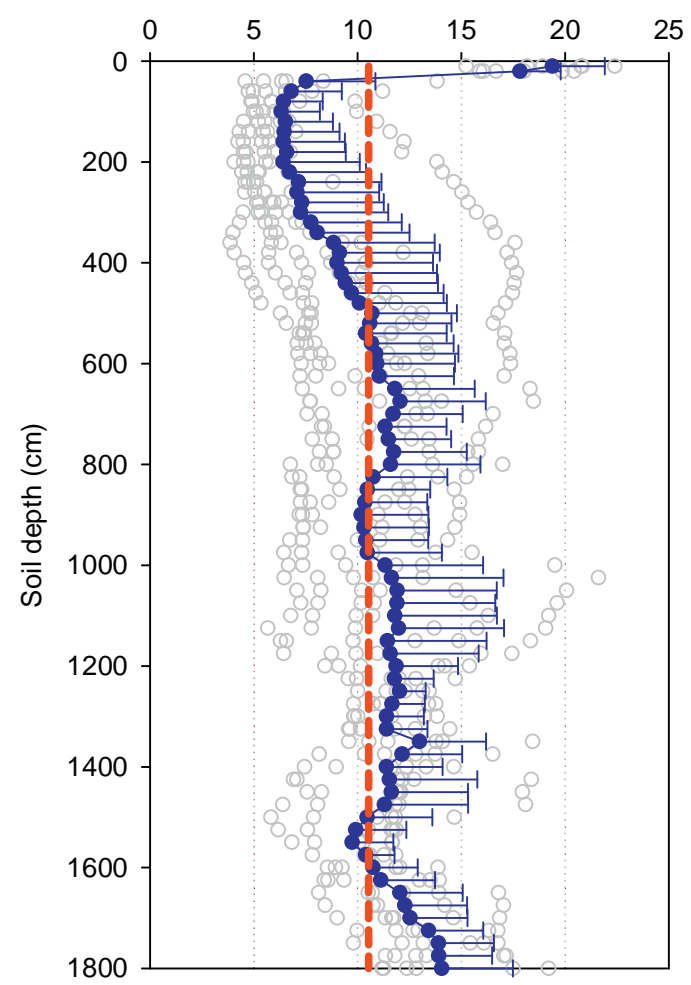

(b) Coefficient of variation (\%)

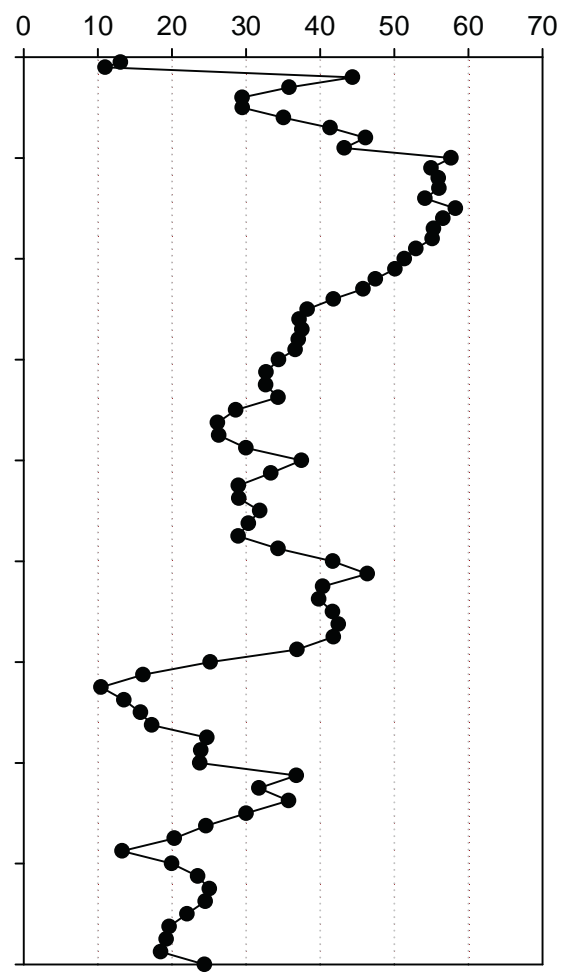

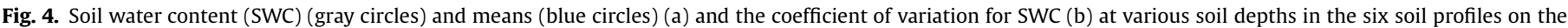

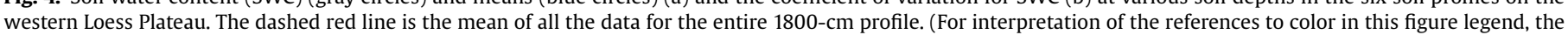
reader is referred to the web version of this article.)

further verified by the ratio between AW and ASWC (Fig. 6). The mechanisms of land-use patterns that shape the patterns of deep soil water may include (1) the differences in plant eco-physiological functions for the different land-use patterns, such as photosynthesis and transpiration, the depth of root distribution (Fig. 3) and processes associated with the uptake of water (van Ek et al., 2000; Xue et al., 2013), and (2) the complex biological, physical and chemical interactions among the plant species in the different land-use patterns that occur both below and above the soil surface (Jing et al., 2013; Liu et al., 2012). The trends in the $1800-\mathrm{cm}$ profiles of available water visually indicated the formation of DSLs and the limited availability for plant growth, so mediating the conditions of soil water in deep soils by configuring different land-use patterns in this region is possible.

\subsubsection{Dried soil layers}

The characteristics of the DSLs under the various land-use patterns are listed in Table 4. DSLs were found in the soil profiles at each pattern, but their extent varied greatly. Soil desiccation was weakest in the farmland (DSLT $=40 \mathrm{~cm}$ ), followed by the grassland $(D S L T=160 \mathrm{~cm})$, and was worst in the shrublands $($ DSLT $=1700 \mathrm{~cm})$, except in S-O. The different patterns of land uses had led to different soil-water-plant environments.

Our data effectively verified that mediating the land-use patterns can substantially improve the profile of soil water and thus may be able to reclaim the DSL. We can clearly reach a reversal of DSL formation if rainwater recharge can be facilitated by reducing the water demands of the plants (Wang et al., 2010b), for example by changing the consumption of water in the land-use pattern from high to low (Yang et al., 2012).

\subsection{Aboveground biomass of C. korshinskii and grassland}

Fig. 7 presents the aboveground biomass of $C$. korshinskii in the shrubland and grassland during the non-growing and growing seasons and their net primary productivities. As expected, $S$ had the highest aboveground biomass of $C$. korshinskii during both the non-growing and growing seasons, compared with S-O, S-G and S-Alf because a large proportion of the $C$. korshinskii coverage (approximately 70\%) was in S, while the coverage of $C$. korshinskii was generally less than $50 \%$ in the three mixed shrublands (Table 1). In comparison, the aboveground biomasses of the

Table 3

Statistics of soil water content to a depth of $1800 \mathrm{~cm}$ under different land-use patterns $(N=6)$ in the semiarid region of the Loess Plateau.

\begin{tabular}{|c|c|c|c|c|c|c|c|c|}
\hline Land-use patterns & $n$ & Minimum (\%) & Maximum (\%) & Mean $(\%)^{a}$ & CV (\%) & Skewness & Kurtosis & $\mathrm{K}-\mathrm{S}$ values \\
\hline Farmland & 79 & 9.9 & 21.6 & $15.2 \mathrm{a}$ & 17 & -0.135 & -0.501 & 0.72 \\
\hline Grassland & 79 & 5.0 & 20.8 & $11.4 \mathrm{~b}$ & 32 & 0.274 & -0.306 & 0.67 \\
\hline Shrubland & 79 & 4.4 & 20.8 & $8.3 c$ & 36 & 1.864 & 6.018 & 0.11 \\
\hline$S-G$ & 79 & 5.2 & 22.4 & $9.9 d$ & 30 & 1.266 & 3.403 & 0.39 \\
\hline S-Alf & 79 & 4.1 & 18.2 & $8.0 \mathrm{c}$ & 33 & 1.322 & 2.704 & 0.08 \\
\hline $\mathrm{S}-\mathrm{O}$ & 79 & 3.9 & 19.2 & $10.5 b d$ & 41 & -0.141 & -1.151 & 0.02 \\
\hline
\end{tabular}

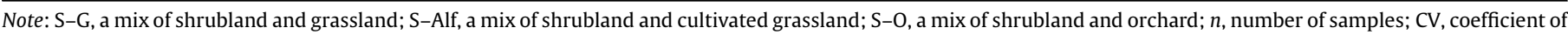
variation; K-S, Kolmogorov-Smirnov test.

${ }^{a}$ Different lowercase letters indicate significant differences $(P<0.05)$ between mean soil water content under different land-use patterns. 


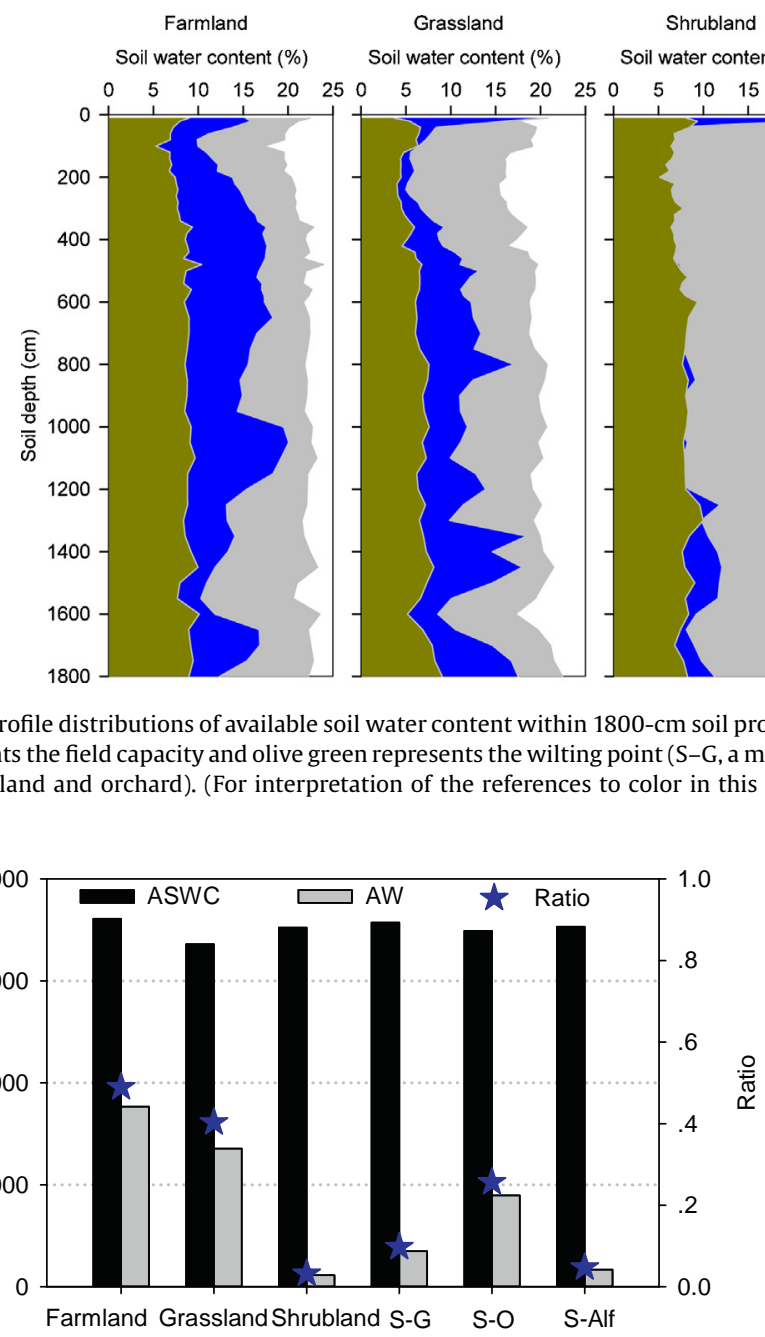

Fig. 6. The available soil water-holding capacity (ASWC) and available soil water (AW) from 0 to $1800 \mathrm{~cm}$ soil depths of different land-use patterns in the gully regions of the western Loess Plateau. The blue star was the ratio between ASW and ASWC (S-G, a mix of shrubland and grassland; S-Alf a mix of shrubland and cultivated grassland, S-O: a mix of shrubland and orchard). (For interpretation of the references to color in this figure legend, the reader is referred to the web version of this article.)

grassland during both the non-growing $\left(140 \mathrm{~g} \mathrm{~m}^{-2}\right)$ and growing $\left(370 \mathrm{~g} \mathrm{~m}^{-2}\right)$ seasons were significantly higher than that of $C$. korshinskii in $\mathrm{S}$, which was understandable due to the high coverage (>90\%) and long-term stability of the grassland ecosystem (Fig. 2).

The ANPPs of $C$. korshinskii and of the grassland demonstrated a similar trend. Grassland had the highest ANPP of $2.0 \mathrm{~g} \mathrm{~m}^{-2} \mathrm{~d}^{-1}$, followed by the $C$. korshinskii in $\mathrm{S}\left(0.5 \mathrm{~g} \mathrm{~m}^{-2} \mathrm{~d}^{-1}\right)$. The $\mathrm{S}-\mathrm{O}$ had the lowest ANPP $\left(0.1 \mathrm{~g} \mathrm{~m}^{-2} \mathrm{~d}^{-1}\right)$ (Fig. 7b). The amount of ANPP can reflect, to some extent, the sensitivity of plant growth to the replenishment of soil water by rainwater, because water availability is a key factor that limits the productivity of plants grown in many environments (Mendham et al., 2011). ANPP is more sensitive to replenishment by rainwater in drier soils. This relationship is consistent with the results of Huang and Gallichand (2006) who found that the yield of apple orchards substantially depended on the dynamics of the soil-water profile after a DSL was formed in the profile. Mendham et al. (2011) also reported that the productivity in the second rotation was lower than that in the first rotation, which may have been partly due to the changes in the stores of soil water in the second rotation.

The competition among the plant species for light and water would affect the levels of aboveground biomass and ANPP. Plants with shallower roots can only compete for water in their vadose zone and not below it, which leads to a different soil-water regime in the study area. The competition for light in our study area was weak enough to be neglected, because the species investigated were generally lower than $1.5 \mathrm{~m}$ (C. korshinskii had a competitive advantage). Zhou et al. (2006) reported that land use in a semiarid steppe ecosystem not only affected the ANPPs of the plants but also species richness, species diversity and the relationship between species diversity and ANPP. In semiarid regions, however, the effect of land use on ANPP in turn may be influenced by water supply and may even be overshadowed by the dominating effect of water stress (Asadi et al., 2012).

The stage of growth of plants may highly affect the amount and distribution of soil water in both the upper and deeper soil layers. A plant has different characteristics of water consumption, stomatal conductance, transpiration capacity and rooting depth at different stages of growth, which thus lead to different soil-water regimes (Nosetto et al., 2005). DSLs differ significantly at different stages of

Table 4

Root depths and characteristics of the dried soil layers (DSLs) under different land-use patterns in the semiarid region of the Loess Plateau.

\begin{tabular}{|c|c|c|c|c|}
\hline Land-use pattern & Sampling depth $(\mathrm{cm})$ & Root depth (cm) & $\operatorname{DSLT}(\mathrm{cm})$ & $\operatorname{DSLFD}(\mathrm{cm})$ \\
\hline Farmland & 1800 & 120 & 40 & 100 \\
\hline Grassland & 1800 & 220 & 160 & 100 \\
\hline Shrubland & 1800 & 1800 & 1700 & 100 \\
\hline$S-G$ & 1800 & 560 & 1700 & 100 \\
\hline S-Alf & 1800 & 1550 & 1700 & 100 \\
\hline $\mathrm{S}-\mathrm{O}$ & 1800 & 600 & 780 & 100 \\
\hline
\end{tabular}

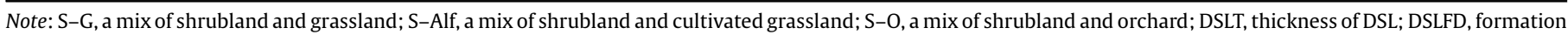
depth of DSL. 


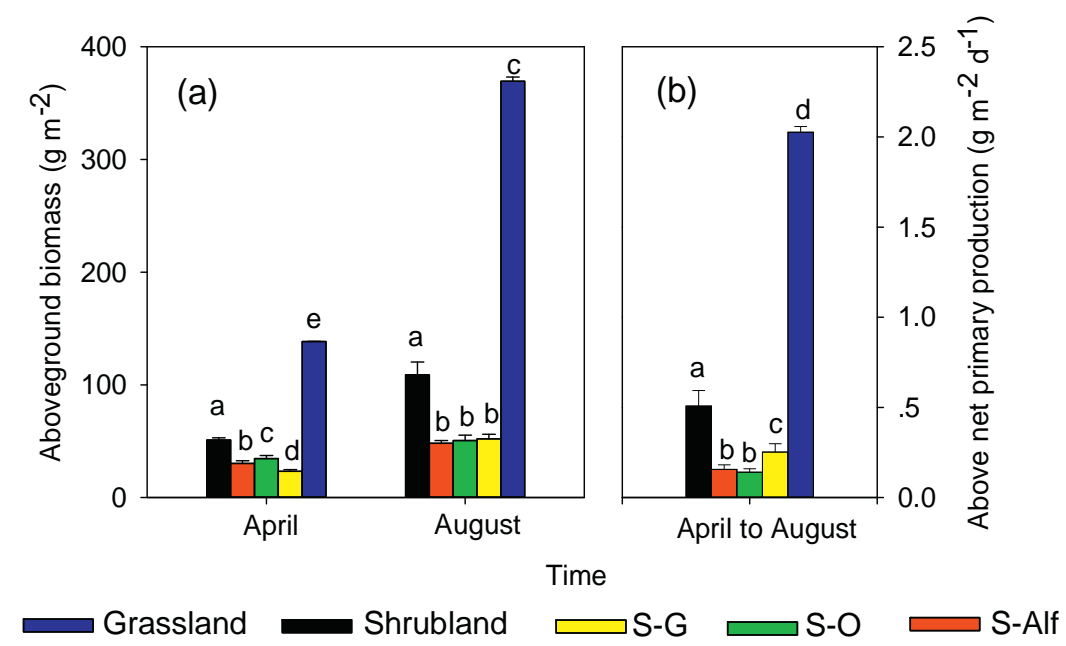

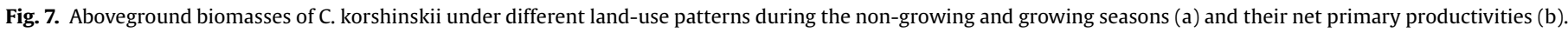

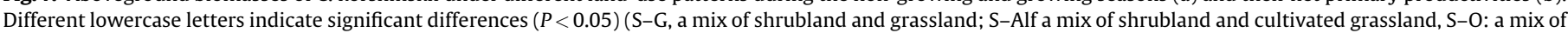
shrubland and orchard).

growth for plant species such as C. korshinskii (Yang, 2001), alfalfa (Li and Huang, 2008) and Black Locust (Robinia pseudoacacia) (Wang et al., 2012a), while the trends of changes are similar for the various plant species as they age.

Scientists, policy makers and land managers require information to support their decisions involving land use and options of plant species. The ecological restoration on the Loess Plateau and other water-limited regions around the world requires a systematic consideration of (1) the dynamics of water both in time and space, (2) the transportation of water in the soil-plant-atmosphere continuum and (3) the planning of sustainable land uses (Wang et al., 2009). Choosing reasonable land-use patterns and suitable species are thus crucial because the shortage of water is a key factor. Using the Soil and Water Assessment Tool, Wang et al. (2010a) suggested that the development of the best management practices for watershed health and sustainability may need to consider the interactive effects between land use and soil. Moreover, the restoration of vegetation on the CLP should also take into account that rainwater is the only source of water recharge for sustaining plant growth (Chen et al., 2007a).

We have comprehensively investigated the conditions of the soil water in a deep profile (Figs. 5 and 6), the characteristics of DSLs (Table 4) and the aboveground biomasses and ANPPs of the plants on the Loess Plateau (Fig. 7). We recommend that grassland would be an optimal use of the land for restoring the fragile environment in this semiarid region of China. Jiang et al. (2013) reconstructed the natural vegetation of the CLP since the last glacial maximum by analyzing pollen samples from six loessial sections and also recommended that the ecological restoration of herbs (e.g., Corylus, Juglans and Selaginella sinensis) should be considered a priority on the CLP. Other studies of semiarid regions around the world have reached similar conclusions, although the factors considered were different from those of the current study. Abdelkadir and Yimer (2011), for example, evaluated the infiltration rate, runoff and SWC $(0-100 \mathrm{~cm}$ depth) for three land-use patterns and concluded that sustainable ecosystemic functioning in the semiarid zone of Ethiopia required a well-regulated grazing system. Paz-Kagan et al.(2014)also reported that transitions from grazing to natural ecosystems in Israel had led to an increase in both soil quality and ANPP.

Our data indicated that grassland can effectively maintain the dynamic balance of the water cycle (i.e., weak and reclaimable soil desiccation and a high ability to buffer water deficits caused by climatic change), plant growth (i.e., no "small-aged trees", the healthy growth of plants and normal ecological services) and ecosystemic stability (i.e., sustainable vegetational succession). The other patterns of land use (i.e., S, S-O, S-G and S-Alf) led to soil desiccation and relatively low ANPP. Farmland had a good condition of soil water, but this type of land use may lead to serious soil erosion due to its low and variable vegetational coverage; therefore farmland is also not sustainable under similar site conditions. Grassland should be the optimal land-use pattern for restoring eco-environments in the semiarid regions of the CLP. The specific management treatments (e.g., grazing, harvesting, irrigation and nitrogen fertilization), characteristics of the plant communities (e.g., coverage, plant density and species richness) and soil properties (e.g., SOC, bulk density and eukaryotes) of the grassland, however, require further study (Fehmi and Kong, 2012; Han et al., 2013; Jing et al., 2014a; Jing et al., 2014b; Lu et al., 2011). Our results provide important information on the status of soil water to a depth of $1800 \mathrm{~cm}$ and on the response of aboveground ANPP to the different patterns of land use. The recommended optimal pattern of land use may accordingly represent an important contribution to the ecological restoration of the Loess Plateau in China and possibly of other arid and semiarid regions around the world.

\section{Conclusions}

The patterns of vertical distribution and amounts of soil water within the $1800-\mathrm{cm}$ profile differed greatly among the six selected land-use patterns. The mean SWC of the farmland at a depth of $1800 \mathrm{~cm}$ was significantly highest, followed by the grassland, and SAlf was the lowest. The AW, the ratio AW/ASWC and the DSLT showed trends similar to that of SWC. The aboveground biomasses and ANPP of the grassland during both the non-growing and growing seasons were significantly higher than those of the shrublands. The soilwater regime within an $1800-\mathrm{cm}$ profile in this semiarid region of the CLP was mainly influenced by the land-use patterns. The data for SWC, AW, DSLT and ANPP indicated that grassland would be an optimal use of the land for restoring the fragile environment in this semiarid region of China. This recommendation may also be helpful to the ecological scientists and policy makers working on similar water-limited regions around the world.

\section{Acknowledgement}

This research was supported by the National Natural Science Foundation of China (Project nos. 41101204, 51179180 and 41471189), the New Star Foundation on Shaanxi Province Youth 
Science and Technology (2013KJXX-09), and West Light Foundation of the Chinese Academy of Sciences.

\section{References}

Abdelkadir, A., Yimer, F., 2011. Soil water property variations in three adjacent land use types in the Rift Valley area of Ethiopia. J. Arid Environ. 75 (11), 1067-1071.

Asadi, H., Raeisvandi, A., Rabiei, B., Ghadiri, H., 2012. Effect of land use and topography on soil properties and agronomic productivity on calcareous soils of a semiarid region, Iran. Land Degrad. Dev. 23 (5), 496-504.

Breshears, D.D., Cobb, N.S., Rich, P.M., Price, K.P., Allen, C.D., Balice, R.G., Romme, W. H., Kastens, J.H., Floyd, M.L., Belnap, J., Anderson, J.J., Myers, O.B., Meyer, C.W., 2005. Regional vegetation die-off in response to global-change-type drought. Proc. Natl. Acad. Sci. U. S. A. 102 (42), 15144-15148.

Canadell, J., Jackson, R.B., Ehleringer, J.R., Mooney, H.A., Sala, O.E., Schulze, E.D., 1996. Maximum rooting depth of vegetation types at the global scale. Oecologia 108, 583-595.

Chen, H.S., Shao, M.A., Li, Y.Y., 2008. Soil desiccation in the Loess Plateau of China. Geoderma 143, 91-100.

Chen, L.D., Huang, Z.L., Gong, J., Fu, B.J., Huang, Y.L., 2007a. The effect of land cover/ vegetation on soil water dynamic in the hilly area of the loess plateau, China. Catena 70 (2), 200-208.

Chen, L.D., Wei, W., Fu, B.J., Lü, Y.H., 2007b. Soil and water conservation on the Loess Plateau in China: review and perspective. Prog. Phys. Geogr. 31 (4), 389-403.

Chen, X., Zhang, Z.C., Chen, X.H., Shi, P., 2009. The impact of land use and land cover changes on soil moisture and hydraulic conductivity along the karst hillslopes of southwest China. Environ. Earth Sci. 59 (4), 811-820.

Cheng, X., Huang, M., Shao, M., Warrington, D.N., 2009. A comparison of fine root distribution and water consumption of mature Caragana korshinkii Kom grown in two soils in a semiarid region, China. Plant Soil 315 (1-2), 149-161.

Davidson, E., Lefebvre, P.A., Brando, P.M., Ray, D.M., Trumbore, S.E., Solorzano, L.A., Ferreira, J.N., Bustamante, M.M.D., Nepstad, D.C., 2011. Carbon inputs and water uptake in deep soils of an eastern amazon forest. Forest Sci. 57 (1), 51-58.

Fang, X., Xue, Z.J., Li, B.C., An, S.S., 2012. Soil organic carbon distribution in relation to land use and its storage in a small watershed of the Loess Plateau, China. Catena 88 (1), 6-13.

Fehmi, J.S., Kong, T.M., 2012. Effects of soil type, rainfall, straw mulch, and fertilizer on semi-arid vegetation establishment, growth and diversity. Ecol. Eng. 44, 70-77.

Gao, L., Shao, M.A., 2012. Temporal stability of soil water storage in diverse soil layers. Catena 95, 24-32.

Grassini, P., You, J., Hubbard, K.G., Cassman, K.G., 2010. Soil water recharge in a semiarid temperate climate of the Central U.S. Great Plains. Agric. Water Manage. 97 (7), 1063-1069.

Han, X.W., Tsunekawa, A., Tsubo, M., Shao, H.B., 2013. Responses of plant-soil properties to increasing $\mathrm{N}$ deposition and implications for large-scale ecorestoration in the semiarid grassland of the northern Loess Plateau, China. Ecol. Eng. 60, 1-9.

Hu, W., Shao, M.A., Han, F.P., Reichardt, K., Tan, J., 2010. Watershed scale temporal stability of soil water content. Geoderma 158 (3-4), 181-198.

Huang, M.B., Gallichand, J., 2006. Use of the SHAW model to assess soil water recovery after apple trees in the gully region of the Loess Plateau, China. Agric. Water Manage. 85 (1-2), 67-76.

Jiang, W., Cheng, Y., Yang, X., Yang, S., 2013. Chinese Loess Plateau vegetation since the Last Glacial Maximum and its implications for vegetation restoration. J. Appl. Ecol. 50 (2), 440-448.

Jing, Z., Cheng, J., Jin, J., Su, J., Bai, Y., 2014a. Revegetation as an efficient means of improving the diversity and abundance of soil eukaryotes in the Loess Plateau of China. Ecol. Eng. 70 (0), 169-174.

Jing, Z.B., Cheng, J.M., Chen, A., 2013. Assessment of vegetative ecological characteristics and the succession process during three decades of grazing exclusion in a continental steppe grassland. Ecol. Eng. 57, 162-169.

Jing, Z.B., Cheng, J.M., Su, J.H., Bai, Y., Jin, J.W., 2014b. Changes in plant community composition and soil properties under 3-decade grazing exclusion in semiarid grassland. Ecol. Eng. 64, 171-178.

Jipp, P.H., Nepstad, D.C., Cassel, D.K., Carvalho, C., 1998. Deep soil moisture storage and transpiration in forests and pastures of seasonally-dry Amazonia. Clim. Change 39, 395-412.

Josa, R., Jorba, M., Vallejo, V.R., 2012. Opencast mine restoration in a Mediterranean semi-arid environment: failure of some common practices. Ecol. Eng. 42, 183-191.

Li, J., Chen, B., Li, X.F., Zhao, Y.J., Ciren, Y.J., Jiang, B., Hu, W., Cheng, J.M., Shao, M.A., 2008. Effects of deep soil desiccation on artificial forestlands in different vegetation zones on the Loess Plateau of China. Acta Ecol. Sin. 28 (4), 1429-1445.

Li, Y.S., 1983. The properties of water cycle in soil and their effect on water cycle for land in the Loess Plateau. Acta Ecol. Sin. 3 (2), 91-101 (in Chinese with English abstract).

Li, Y.S., Huang, M.B., 2008. Pasture yield and soil water depletion of continuous growing alfalfa in the Loess Plateau of China. Agric. Ecosyst. Environ. 124 (1-2), $3-12$.
Liu, W., Sang, T., 2013. Potential productivity of the Miscanthus energy crop in the Loess Plateau of China under climate change. Environ. Res. Lett. 8 (4), 44003.

Liu, W.Z., Zhang, X.C., Dang, T.H., Ouyang, Z., Li, Z., Wang, J., Wang, R., Gao, C., 2010 Soil water dynamics and deep soil recharge in a record wet year in the southern Loess Plateau of China. Agric. Water Manage. 97 (8), 1133-1138.

Liu, X.P., Zhang, W.J., Yang, F., Zhou, X., Liu, Z.J., Qu, F., Lian, S.Q., Wang, C.L., Tang, X.G., 2012. Changes in vegetation-environment relationships over long-term natural restoration process in middle Taihang Mountain of North China. Ecol. Eng. 49, 193-200.

Lu, X.T., Cui, Q.A., Wang, Q.B., Han, X.G., 2011. Nutrient resorption response to fire and nitrogen addition in a semi-arid grassland. Ecol. Eng. 37 (3), 534-538.

Lu, Y.H., Fu, B.J., Feng, X.M., Zeng, Y., Liu, Y., Chang, R.Y., Sun, G., Wu, B.F., 2012. A policy-driven large scale ecological restoration: quantifying ecosystem services changes in the Loess Plateau of China. PLoS One 7 (2), e31782.

Markewitz, D., Devine, S., Davidson, E.A., Brando, P., Nepstad, D.C., 2010. Soil moisture depletion under simulated drought in the Amazon: impacts on deep root uptake. New Phytol. 187 (3), 592-607.

Mendham, D.S., White, D.A., Battaglia, M., McGrath, JF, Short, T.M., Ogden, G.N Kinal, J., 2011. Soil water depletion and replenishment during first- and early second-rotation Eucalyptus globulus plantations with deep soil profiles. Agric. Forest Meteorol. 151 (12), 1568-1579.

Nepstad, D.C., Decarvalho, C.R., Davidson, E.A., Jipp, P.H., Lefebvre, P.A., Negreiros, G. H., Dasilva, E.D., Stone, T.A., Trumbore, S.E., Vieira, S., 1994. The role of deep roots in the hydrological and carbon cycles of amazonian forests and pastures. Nature 372 (6507), 666-669.

Nosetto, M.D., Jobbagy, E.G., Paruelo, J.M., 2005. Land-use change and water losses: the case of grassland afforestation across a soil textural gradient in central Argentina. Glob. Change Biol. 11 (7), 1101-1117.

Paz-Kagan, T., Shachak, M., Zaady, E., Karnieli, A., 2014. Evaluation of ecosystem responses to land-use change using soil quality and primary productivity in a semi-arid area. Israel Agric. Ecosyst. Environ. 193, 9-24.

Shi, H., Shao, M.A., 2000. Soil and water loss from the Loess Plateau in China. J. Arid Environ. 45, 9-20.

Stephen, S.O.B., Mark, A.A., Neil, C.T., Don, A.W., Chin, K.O., 2001. Tree roots: conduits for deep recharge of soil water. Oecologia 126 (2), 158-165.

van Ek, R., Witte, J.P.M., Runhaar, H., Klijn, F., 2000. Ecological effects of water management in the Netherlands: the model DEMNAT. Ecol. Eng. 16 (1), 127-141.

Wang, L., Wang, Q.J., Wei, S.P., Shao, M.A., Li, Y., 2008. Soil desiccation for Loess soils on natural and regrown areas. Forest Ecol. Manage. 255 (7), 2467-2477.

Wang, S., Fu, B.J., Gao, G.Y., Yao, X.L., Zhou, J., 2012a. Soil moisture and evapotranspiration of different land cover types in the Loess Plateau, China. Hydrol. Earth Syst. Sci. 16 (8), 2883-2892.

Wang, X.X., Shang, S.Y., Yang, W.H., Clary, C.R., Yang, D.W., 2010a. Simulation of land use-soil interactive effects on water and sediment yields at watershed scale. Ecol. Eng. 36 (3), 328-344.

Wang, Y.Q. Shao, M.A., Liu, Z.P., 2010b. Large-scale spatial variability of dried soil layers and related factors across the entire Loess Plateau of China. Geoderma 159 (1-2), 99-108.

Wang, Y.Q., Shao, M.A., Liu, Z.P., 2013. Vertical distribution and influencing factors of soil water content within 21-m profile on the Chinese Loess Plateau. Geoderma 193-194, 300-310.

Wang, Y.Q., Shao, M.A., Liu, Z.P., Warrington, D.N., 2012b. Regional spatial pattern of deep soil water content and its influencing factors. Hydrol. Sci. J. 57 (2), 265-281.

Wang, Y.Q., Shao, M.A., Zhu, Y.J., Liu, Z.P., 2011. Impacts of land use and plant characteristics on dried soil layers in different climatic regions on the Loess Plateau of China. Agric. Forest Meteorol. 151 (4), 437-448.

Wang, Z.Q., Liu, B.Y., Liu, G., Zhang, Y.X., 2009. Soil water depletion depth by planted vegetation on the Loess Plateau. Sci. China Ser. D: Earth Sci. 52 (6), 835-842.

Xue, Z.J., Cheng, M., An, S.S., 2013. Soil nitrogen distributions for different land uses and landscape positions in a small watershed on Loess Plateau, China. Ecol. Eng. 60, 204-213.

Yang, L., Wei, W., Chen, L., Mo, B., 2012. Response of deep soil moisture to land use and afforestation in the semi-arid Loess Plateau, China. J. Hydrol. 475 (0), $111-122$.

Yang, W.Z., 2001. Soil water resources and afforestation in Loess Plateau. J. Nat. Res. 16 (5), 433-438 (in Chinese with English abstract).

Zavaleta, E.S., Thomas, B.D., Chiariello, N.R., Asner, G.P., Shaw, M.R., Field, C.B., 2003 Plants reverse warming effect on ecosystem water balance. Proc. Natl. Acad. Sci. U. S. A. 100 (17), 9892-9893.

Zhang, F., Xing, Z.S., Rees, H.W., Dong, Y.L., Li, S., Meng, F.R., 2014. Assessment of effects of two runoff control engineering practices on soil water and plant growth for afforestation in a semi-arid area after 10 years. Ecol. Eng. 64, 430-442.

Zhao, Z., Cai, Y., Fu, M., Bai, Z., 2008. Response of the soils of different land use types to drought: eco-physiological characteristics of plants grown on the soils by pot experiment. Ecol. Eng. 34 (3), 215-222.

Zhou, Z., Sun, O.J., Huang, J., Gao, Y., Han, X., 2006. Land use affects the relationship between species diversity and productivity at the local scale in a semi-arid steppe ecosystem. Funct. Ecol. 20 (5), 753-762. 